\title{
Cultivation of Spore-Forming Gut Microbes Using a Combination of Bile Acids and Amino Acids
}

\author{
Sakura Onizuka, Masaru Tanaka, Riko Mishima and Jiro Nakayama * \\ Department of Bioscience and Biotechnology, Faculty of Agriculture, Kyushu University, Nishi-ku, \\ Fukuoka 819-0395, Japan; zuzuko4541@gmail.com (S.O.); msr456852@gmail.com (M.T.); \\ r.mishima3519@gmail.com (R.M.) \\ * Correspondence: nakayama@agr.kyushu-u.ac.jp; Tel.: +81-92-802-4737
}

Citation: Onizuka, S.; Tanaka, M.;

Mishima, R.; Nakayama, J.

Cultivation of Spore-Forming Gut

Microbes Using a Combination of Bile

Acids and Amino Acids.

Microorganisms 2021, 9, 1651.

https://doi.org/10.3390/

microorganisms 9081651

Academic Editor: Mitsuo Sakamoto

Received: 30 June 2021

Accepted: 28 July 2021

Published: 2 August 2021

Publisher's Note: MDPI stays neutral with regard to jurisdictional claims in published maps and institutional affiliations.

\begin{abstract}
Spores of certain species belonging to Firmicutes are efficiently germinated by nutrient germinators, such as amino acids, in addition to bile acid. We attempted to culture difficult-to-culture or yet-to-be cultured spore-forming intestinal bacteria, using a combination of bile acids and amino acids. The combination increased the number of colonies that formed on agar medium plated with ethanol-treated feces. The operational taxonomic units of these colonized bacteria were classified into two types. One type was colonized only by the bile acid (BA) mixture and the other type was colonized using amino acids, in addition to the BA mixture. The latter contained 13 species, in addition to 14 species of the former type, which mostly corresponds to anaerobic difficult-to-culture Clostridiales species, including several new species candidates. The use of a combination of BAs and amino acids effectively increased the culturability of spore-forming intestinal bacteria.
\end{abstract}

Keywords: gut microbiota; cultivation; spore; germination; co-germinant; bile acid; amino acid

\section{Introduction}

The human intestinal system is inhabited by a wide variety of bacteria. They interact to form complex intestinal microbiota that influence various activities and the health of the host [1,2]. The development of metagenomic sequence technology, which digitizes genetic components of gastrointestinal microbiota, has enabled the discoveries of host-independent metabolic functions of the intestinal microbial community, such as the synthesis of vitamins or neurotransmitters, and the digestion of dietary fibers followed by the fermentative production of organic acids, which play important roles in host energy and immune homeostasis, as well as protection against infection by pathogens [3-7]. However, there are limitations in these culture-independent methods, which are currently mainstream of gut microbiology, for gaining bottom-up insights in the gut microbial community. Further understanding of the roles of each intestinal bacterial member in the community requires the isolation and culture of bacteria from the 4500 species estimated by metagenomic studies, among which 1900 have yet to be cultured [8].

Clostridiales is a dominant order in the human large intestine. Species belonging to this order are mostly known as spore-forming species, some of which are substantially involved in human health and disease [9-11]. Spores are durable forms of cells, with a completely different structure than vegetative cells, which allows them to survive in unfavorable environmental conditions, such as nutrient deprivation, desiccation, and exposure of strictly anaerobic bacteria to oxygen [12-15].

The human body harbors two major types of bile acids (BAs), which are cholic acid (CA) and chenodeoxycholic acid (CDCA). Both are synthesized as conjugated forms in the liver, from cholesterol [16]. These BAs are stored in the gallbladder, and released into the duodenum in response to dietary lipids $[17,18]$. In the digestive tract, residential bacteria deconjugate CA and CDCA. Subsequent dihydroxylation or epimerization at the C-7 position results in secondary BAs that include deoxycholic acid (DCA), lithocholic 
acid (LCA), and ursodeoxycholic acid (UDCA) [19-21]. Fifteen different BA molecules are predominant in the human intestinal tract. Spores of Clostridium difficile germinate in response to taurocholic acid (TCA) [22-24]. TCA acts as a potent germinator for a variety of spore-forming bacteria, including a number of novel species [9]. Following these studies, we examined the germination-inducing activity of these $15 \mathrm{BA}$ molecules. In addition to TCA, the glycine conjugates GCDCA, GDCA, and GCA displayed potent spore germination-inducing activity. These germination-inducing activities have proven useful for the selective culture of spore-forming bacteria containing difficult-to-isolate species or yet-to-be cultured species. For example, we isolated 72 species containing 10 new species candidates [25].

Spores germinate through a complex process, in response to BAs and to specific environmental factors, such as amino acids (AAs), nucleic acids, and sugars, which are indicators of a suitable environment for growth $[26,27]$. For instance, efficient germination of $C$. difficile requires a second co-germinant signal, namely, AAs, notably glycine, in addition to BA [14,24,28-30]. To sense the signal of those germinants, $C$. difficile has a cascade signaling system, consisting of three Csp proteins (CspA, CspB, and CspC) [31-34]. These Csp proteases are conserved in many Clostridiales, such as Clostridiaceae, Lachnospiraceae, and Peptostreptococcaceae $[35,36]$. Further, the germination receptors are diverse, including Ger protein family-sensing AAs in C. perfringens and C. botulinum, in addition to CspCsensing TCA in C. difficile $[37,38]$. It is suspected that diverse germination receptors that recognize various environmental signals, such as AAs, as co-germination signals remain to be identified [34,39].

There may be various modes of action for germination of the extensively diverse variety of bacteria that are present in the human intestine, many of which may require both BAs and nutrient germinants, such as AAs, for efficient germination, as has been observed in C. difficile [39-41]. Therefore, we presume that to enable to culture more diverse sporeforming gut microbes, a combination of BAs and AAs could be used. In this study, we examined the combination of BAs and AAs to expand the spectrum of culturable intestinal bacteria.

\section{Materials and Methods}

\subsection{Fecal Sample Collection}

To investigate the germination activity of the combination of BAs and AAs on bacteria in the gastrointestinal tract, fresh feces were collected from five healthy adults aged 23-35 years, as previously described [25]. The samples were collected in duplicate. One sample was used for bacterial culture in phosphate-buffered saline (PBS). The other sample was collected in RNA later and subsequently used for $16 \mathrm{~S}$ rRNA amplicon sequencing. Samples collected in PBS were processed within $15 \mathrm{~min}$ to maintain the viability of the anaerobic bacteria.

\subsection{Spore Purification}

To obtain spores, fecal samples were processed as described previously [25]. Briefly, the samples were homogenized in PBS followed by the addition of an equal volume of $70 \%(v / v)$ ethanol, and then incubated for $4 \mathrm{~h}$ under ambient aerobic conditions at room temperature to kill vegetative cells. The samples were washed three times with PBS and resuspended in PBS for spreading onto the agar medium.

\subsection{Germination-Inducing Substances}

The BAs used in this study included GCA (Tokyo Chemical Industry Co. Ltd., Tokyo, Japan), GCDCA (Nacalai Tesque, Kyoto, Japan), GDCA (Sigma-Aldrich, St. Louis, MO, USA), TCA (Tokyo Chemical Industry Co., Ltd.), and TCDCA (FUJIFILM Wako Pure Chemical Co., Wako, Japan) (structural information of bile acids used in this study is described in Table S1). GCA, GCDCA, TCA, and TCDCA were dissolved in dimethyl sulfoxide (DMSO) to $5 \%(w / v)$ and filter sterilized. GDCA was dissolved in DMSO to $1 \%$ 
$(w / v)$ and filter sterilized. To prepare the BA mixture, equal volumes of the five bile acids were mixed.

All AAs were the L-form or glycine. They were purchased from Sigma-Aldrich. Stock solutions of AAs were dissolved in water with $\mathrm{pH}$ adjusted to 7.5 , with sodium hydroxide (Nacalai Tesque) and sodium chlorite (Sigma-Aldrich). These solutions were sterilized by filtration before use.

\subsection{Germination and Culturing}

The ethanol-treated samples were suspended in PBS to a final volume of $100 \mu \mathrm{L}$ (containing final concentrations of $30 \mathrm{mM} \mathrm{AA}$ and $2 \%(v / v)$ of the BA mixture). To induce germination, they were incubated in an anaerobic chamber containing $10 \%$ carbon dioxide, $10 \%$ hydrogen, and $80 \%$ nitrogen at $37^{\circ} \mathrm{C}$ for $30 \mathrm{~min}$ and spread on Gifu anaerobic medium (GAM; Nissui Pharmaceutical, Tokyo, Japan) agar plates. The inoculated agar plates were incubated in an anaerobic chamber at $37^{\circ} \mathrm{C}$ for $72 \mathrm{~h}$.

\section{5. $16 S$ rRNA Gene Amplicon Sequencing and Analysis}

16S rRNA gene amplicon sequencing and analysis were performed as previously described [25]. Briefly, all colonies grown on the plate were collected and genomic DNA was extracted from the region of the pooled bacterial cell samples using the bead-phenol method [42]. The DNA was used for amplicon sequencing of the 16S V3-V4 by Illumina MiSeq [42]. The microbiota of fecal samples was also determined using bacterial genomic DNA extracted by the bead-phenol method from fecal samples and the V3-V4 amplicon sequencing system in Illumina MiSeq. The obtained sequence data were dereplicated into operational taxonomic units (OTUs) with $97 \%$ sequence identity using the Uparse pipeline in Usearch versions 9.2, 10.0. (http:/ / drive5.com/ usearch/download.html, accessed on 14 December 2020). The representative sequence of each OTU was subjected to species annotation using EZ biocloud 16S-based ID (https: / / www.ezbiocloud.net/identify, accessed on 29 June 2021).

\subsection{Statistical Analyses}

Statistical analyses were performed using the R package (V.4.0.5) (https: / /www.rproject.org/, accessed on 14 December 2020) and Excel 2019 (Microsoft). To compare colony-forming units (CFU) between the treated and control groups, Welch's t-test or Wilcoxon rank sum test was used for triplicate and quintuplicate experiments, respectively. The operational taxonomic units (OTUs) were clustered based on their relative abundances on the 16 different AA plates. The hierarchical clustering was calculated based on the full concatenation of the Euclidean distance matrix using a heatmap function of the R gplot package.

\subsection{Accession Number of $16 S$ rRNA Gene Sequences}

Raw sequence data were deposited in the DNA Data Bank of Japan (DDBJ) sequence read archive (DRA012257) under BioProject no. PRJDB9975, which contains links and access to stool samples and plate colony data under BioSample SAMD00327995 to SAMD00328050.

\subsection{Ethics Approval}

This study was approved by the ethics committee of the Faculty of Agriculture, Kyushu University (No. 19-006). All methods were performed in accordance with relevant guidelines and regulations. Written informed consent was obtained from donors of fecal samples. We entered and analyzed all samples anonymously and published all data anonymously using personal numbers. 


\section{Results}

3.1. Effect of Inidividual AAs on the Germination and Colony-Inducing Activities for Spore-Forming Bacteria in Feces

To evaluate the effect of each AA on the germination and colony-inducing activities independently of BAs, the ethanol-treated fecal samples were exposed to various AAs, and then cultured on GAM agar plates. As a positive control, a sample exposed to a mixture of BAs was spread on the agar plate and cultured using the same procedure. An untreated sample was spread on the plate as a negative control. No statistical increase in CFU was observed in the samples that were treated with any AA, while CFU was significantly increased in the positive control treated with the BA mixture compared to the negative control ( $p<0.01$, Welch's t-test; Figure 1). This result suggests BA-dependent activity of AAs.

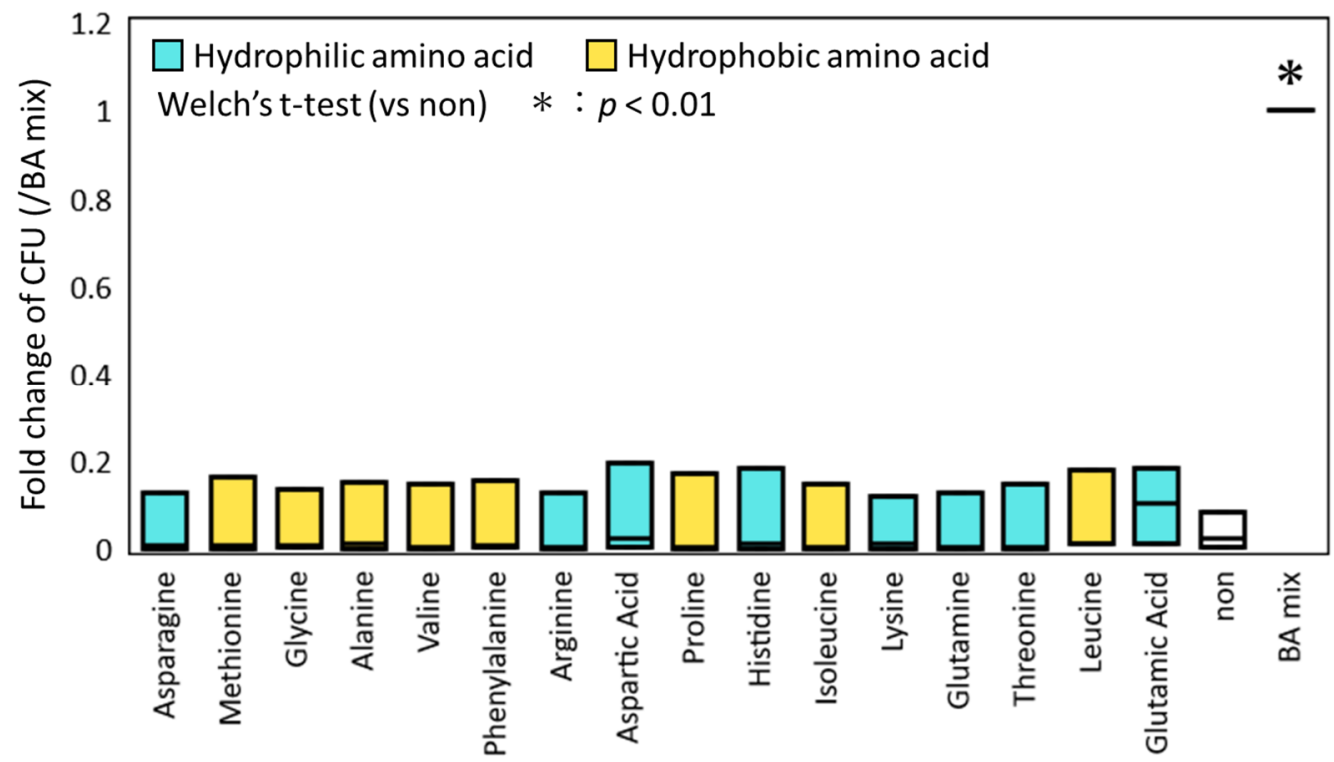

Figure 1. Comparison of fold-change of colony-forming units (CFU) by addition of amino acids (AAs). The ethanol-treated samples collected from three donor subjects were incubated with each AA. The number of colonies that formed on the GAM agar plate was counted after $72 \mathrm{~h}$ incubation. Fold-change was calculated based on the bile acid mixture (BA mixture) for each fecal sample and is shown in the box plot. The Welch's t-test was used to test for significant differences of colony counts between control plate without AA and BA, and plate with AA or BA mixture. The asterisk on the bar represents $p<0.01$.

\subsection{Culturing of Spore-Forming Bacteria in Feces Using a Combination of Various AAs with BAs}

We next examined the combined effect of $\mathrm{AA}$ and BA on the germination/colony induction of spore-forming bacteria in feces. The samples were treated with various AAs, in addition to a mixture of five conjugative BAs (GCA, GCDCA, GDCA, TCA, and TCDCA), which have been indicated to have substantial spore-germinating activity in our previous study [25]. As shown in Figure 2, 12 AAs showed an increasing effect, in which arginine showed statistical significance $(p<0.008$, Wilcoxon rank sum test). The other 11 AAs increased the $\mathrm{CFU}$, ranging from approximately 1 to 1.5 , depending on the samples. However, the differences were not statistically significant. 


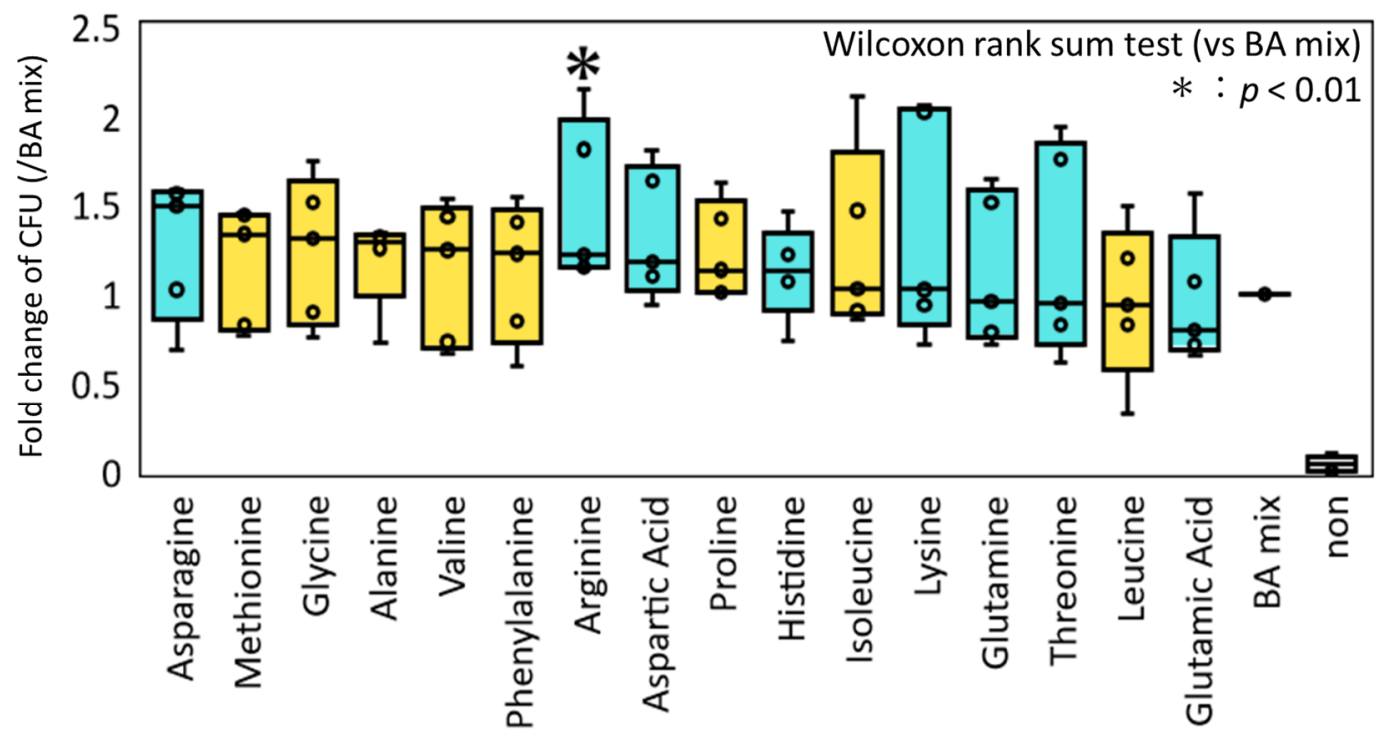

Hydrophilic amino acid $\quad \square$ Hydrophobic amino acid

Figure 2. Comparison of fold-change of CFU by addition of AAs to the mixture of BAs. The ethanol-treated samples collected from five donors were incubated with each AA in addition to the BA mixture. The number of colonies formed on the GAM agar plate was determined after $72 \mathrm{~h}$ incubation. Fold-change was calculated based on the BA mixture for each fecal sample and is shown in the box plot. The samples were arranged in the order of the median fold-change among the five donors. The Wilcoxon rank sum test was used to test for significant differences between the BA mixture and BA plates. The asterisk on the bar represents $p<0.01$.

\subsection{Classification of Germinating Bacteria by Responsiveness to AAs and BAs}

To obtain taxonomic information of the bacteria that germinated and colonized in response to the BA mixture with or without AAs, the colonies grown on each agar plate were pooled and subjected to $16 \mathrm{~S}$ rRNA gene amplicon sequencing. At the same time, total DNA was directly extracted from the donor's fecal samples and subjected to amplicon sequencing. Figure S1 reports the new OTUs appearing in response to AAs. These new OTUs correspond to approximately $15 \%$ of the bacterial population in each donor fecal sample, suggesting the validity of this method to increase the culturability of difficultto-culture bacteria that are present in the feces. The distribution of OTUs that appeared among the different treatments (Figure 3) was subjected to clustering analysis and it is shown as a heat map. The observed OTUs differed in their reactivity to BA and each AA, and were largely classified into two types. The BA type was found even in the samples that were treated only with BA mixture. The BA-AA type was found only in the samples that were treated with AAs, in addition to the BA mixture. The presence of the BA-AA type suggests the effect of the AAs in expanding the spectrum of culturable species.

\subsection{Phylogenetic Analysis of Bacterial Species Germinated by the Combination of BAs and/or AAs}

Phylogenetic analysis of the BA type and BA-AA type bacterial species was performed. Figure 4 shows the closely related species of the BA type and BA-AA type OTUs. The BA type comprised 14 species, and the BA-AA type comprised 13 species. In both types, the OTUs were mainly distributed to the order Closridiales, comprising the family Lachnospiraceae, Clostridiacea, and Osillospiraceae, in addition to other minor Firmicutes groups, such as Erysipelotrichaceae and Bacillaceae. The BA-AA type contains five novel candidate species, showing $<97 \%$ sequence identity in the partial 16S RNA sequence to the closest known species (asterisks in Figure 4), while the BA type contains one novel candidate species. 


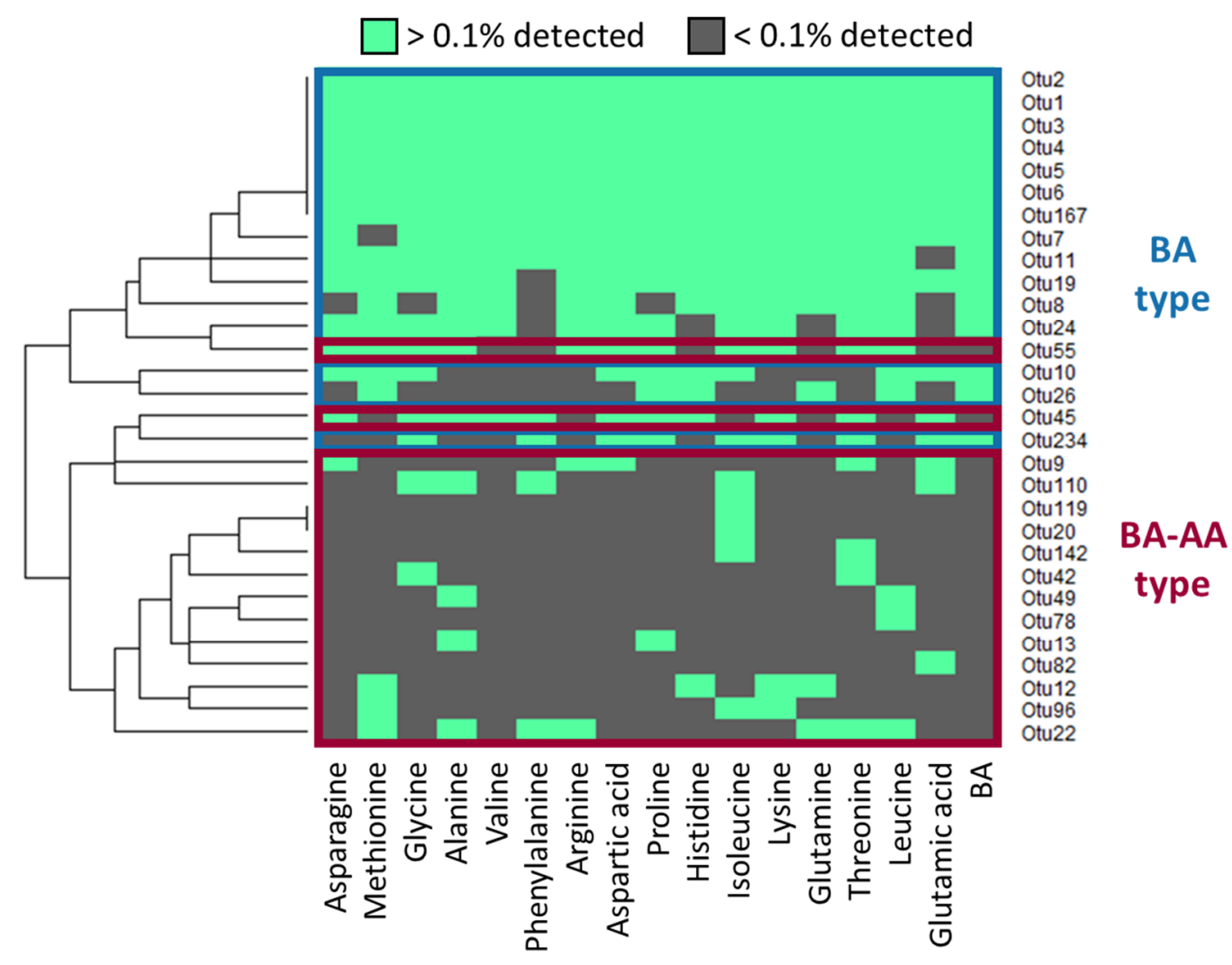

Figure 3. Hierarchical clustering of bacterial operational taxonomic units (OTUs) grown on agar plates supplemented with each AA in addition to the BA mixture. OTUs that accounted for $>0.1 \%$ of total population on each plate were selected and subjected to clustering analysis. They are shown in green in the heat map.

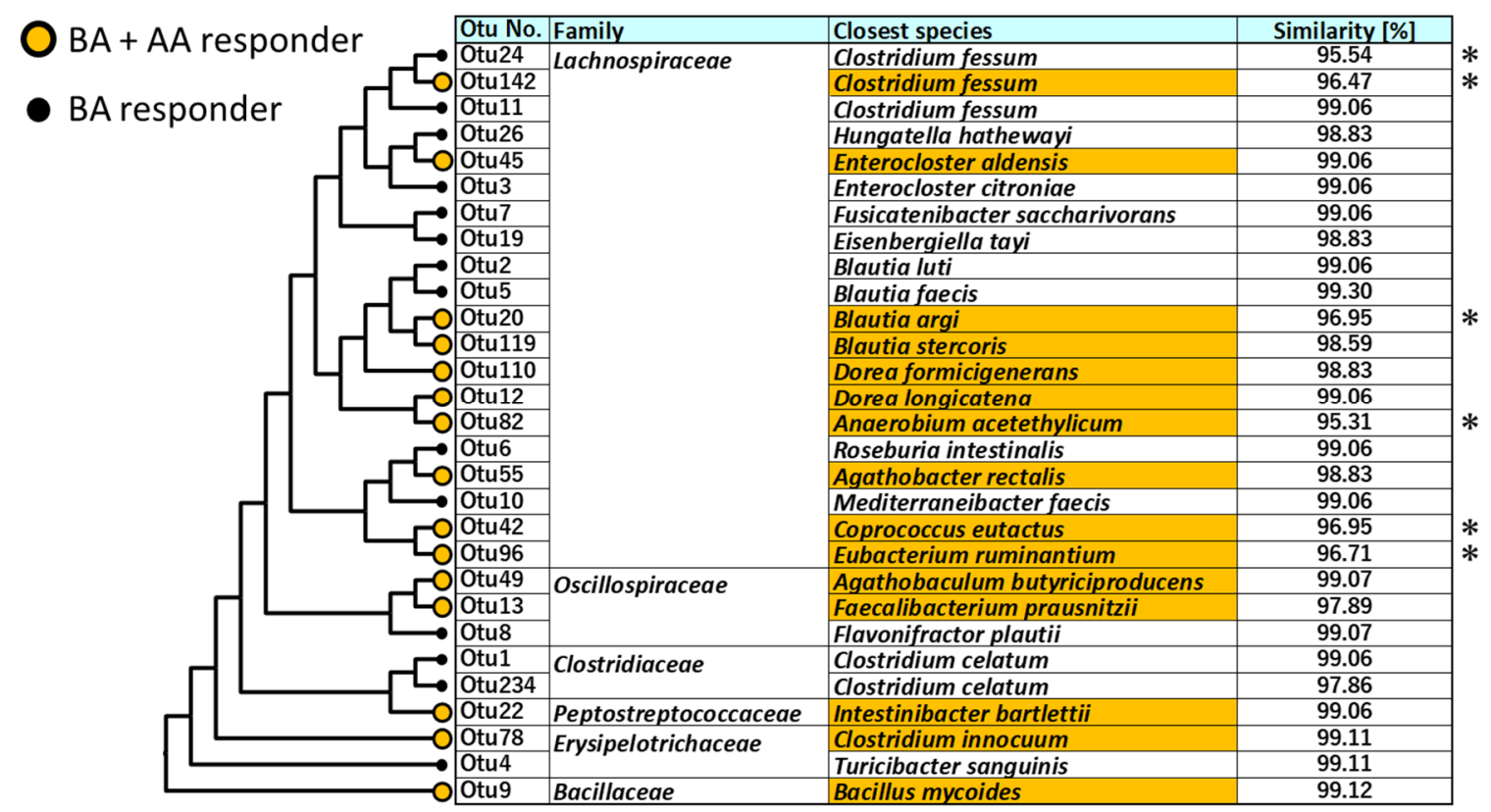

Figure 4. Phylogenetic analysis of BA type and BA-AA type OTUs. The phylogenetic tree was constructed by the neighborjoining method using the sequences of V3-V4 region of the 16S rRNA gene. Colored OTUs represent BA-AA type. Closest species was identified by homology search of the partial $16 \mathrm{~S}$ rRNA sequence to EZ biocloud type strain database. Sequence similarities $<97 \%$ is marked by asterisk. 


\section{Discussion}

Isolation and cultivation are required to fully determine the function of each bacterium in the intestine. However, a large proportion of intestinal bacteria, particularly strictly aerobic Firmicutes species, notably classified as order Clostridiales, are difficult to culture, or have yet to be cultured. This has hindered the study of intestinal microbiology.

In our previous study, we succeeded in addressing the hurdle of cultural isolation of the Clostridiales species, by using the following two aspects of these bacteria: the sporeforming property and the spore-germinating property in response to BAs [25]. In this study, we further enhanced the efficiency of this cultural isolation method using AAs. The protocol of this method is quite simple, and requires only BAs and AAs, in addition to an ordinal anaerobic culture system, but does not require handling of fecal samples under the strictly anaerobic conditions.

In C. difficile, glycine is the most effective co-germinating agent. Other molecules, such as L-phenylalanine, L-arginine, L-cysteine, and L-alanine, also induce spore germination when TCA is added [39-41]. In contrast, AAs with negative charges on their side chains, such as glutamic acid and aspartic acid, function poorly as co-germinants [41]. In the present study, the number of colonies in the samples in which germination was induced by the germination of a mixture of BAs combined with glutamic acid, was lower than that of other AAs, which is similar to the results obtained in previous studies [41].

In the present study, we also found that there are two types of germination-inducing


tivities to germination inducers. Their classification differed at the species level. Earlier studies ranked the germination-inducing activity of various AAs against $C$. difficile, and demonstrated that glycine functioned most effectively as a co-germinant and L-aspartic acid functioned poorly, with a hierarchical ranking of AA co-germination activity [24,39-41]. The ranking of this germination-inducing activity was also slightly different among the strains. Other known spore-forming bacteria of the Bacillus and Clostridium genera have a variety of germination pathways [43-46]. This difference in reactivity and reaction pathways to germinants is suggested by the different OTUs growing in response to different AAs. Glycine, which effectively induces the germination of $C$. difficile spores, is preferentially used in energy generation by AA metabolism via the Stickland reaction [47]. Arginine, which showed a significant increase in colonies in this study, has been suggested to play an important and regulatory role in the physiology of Bacillus, through arginine phosphorylation [48]. Thus, since some AAs are involved in the growth of trophoblast cells, AAs may be involved in the vegetation, as well as germination, of spores. The molecular mechanism on the reception and signal transduction of these germinants and co-germinants, and the following vegetative growth, warrants further studies for a more efficient strategy to address uncultivable spore-forming groups of intestinal bacteria.

The results of the present study suggest that the spectrum of spore-forming bacteria that can be cultured and isolated by BAs can be further expanded by the addition of various AAs. In previous studies, many new candidate species have been successfully isolated by culturing spores with BAs $[9,25]$. Since there are many unknowns in germination by the combination of BAs and AAs, it would be worthwhile to proceed with large-scale isolation and culture studies using these germinants.

Supplementary Materials: The following are available online at https://www.mdpi.com/article/10 .3390 / microorganisms9081651/s1, Figure S1: The population of the OTUs on each plate; Table S1: Structural information on bile acid species used in this study.

Author Contributions: Conceptualization, S.O., M.T. and J.N.; methodology, S.O. and M.T.; validation, S.O., M.T., J.N.; formal analysis, S.O., M.T., R.M.; investigation, S.O., M.T.; data curation, S.O., M.T.; writing-original draft preparation, S.O.; writing—review and editing, M.T., J.N.; visualization, S.O.; supervision, J.N.; project administration, J.N.; funding acquisition, J.N. All authors have read and agreed to the published version of the manuscript. 
Funding: This study was supported by JSPS KAKENHI grant numbers JP 17H04620 and 20KK0130 (to J.N.), funding from the Institute for Fermentation, Osaka (IFO), Japan (to J.N.) and funding from Nagase Science Technology Foundation, Japan (to J.N.).

Institutional Review Board Statement: The study was conducted according to the guideline of the Declaration of Helsinki and approved by the Institutional Review Board of the Faculty of Agriculture, Kyushu University (No. 19-006) on 19 December 2019.

Informed Consent Statement: Informed consent was obtained from all participants involved in the study.

Data Availability Statement: Raw sequence data were deposited in the DNA Data Bank of Japan (DDBJ; https: / /www.ddbj.nig.ac.jp/index-e.html: accessed on 17 June 2021) sequence read archive (DRA012257) under BioProject No. PRJDB9975, which contains links and access to stool sampling and cultured data under BioSample SAMD00327995 to SAMD00328050.

Acknowledgments: We thank all the subjects who provided fecal samples. We appreciate the technical assistance for the operation of MiSeq from the Center for Advanced Instrumental and Educational Supports, Faculty of Agriculture, Kyushu University.

Conflicts of Interest: The authors declare no conflict of interest.

\section{References}

1. Sender, R.; Fuchs, S.; Milo, R. Revised Estimates for the Number of Human and Bacteria Cells in the Body. PLoS Biol. 2016, 14, e1002533. [CrossRef]

2. Lora, V.H.; Littman, D.R.; Macpherson, A.J. Interactions between the microbiota and the immune system. Science 2012, 336, 1268-1273. [CrossRef]

3. Bäckhed, F.; Ley, R.E.; Sonnenburg, J.L.; Peterson, D.A.; Gordon, J.I. Host-bacterial mutualism in the human intestine. Science 2005, 307, 1915-1920. [CrossRef]

4. Tarashi, K.A. The Role of Gut Microbiota in the Development and Function of Intestinal T cells. J. Intest. Microbiol. 2015, 29, 1-7. [CrossRef]

5. Fraune, S.; Bosch, T.C.G. Why bacteria matter in animal development and evolution. BioEssays 2010, 32, 571-580. [CrossRef]

6. Macpherson, A.J.; Köller, Y.; McCoy, K.D. The bilateral responsiveness between intestinal microbes and IgA. Trends Immunol. 2015, 36, 460-470. [CrossRef]

7. Khan, M.T.; Nieuwdorp, M.; Bäckhed, F. Microbial modulation of insulin sensitivity. Cell Metab. 2014, 20, 753-760. [CrossRef] [PubMed]

8. Nayfach, S.; Shi, Z.J.; Seshadri, R.; Pollard, K.S.; Kyrpides, N.C. New insights from uncultivated genomes of the global human gut microbiome. Nature 2019, 568, 505-510. [CrossRef] [PubMed]

9. Browne, H.P.; Forster, S.C.; Anonye, B.O.; Kumar, N.; Neville, B.A.; Stares, M.D.; Goulding, D.; Lawley, T.D. Culturing of "unculturable" human microbiota reveals novel taxa and extensive sporulation. Nature 2016, 533, 543-546. [CrossRef] [PubMed]

10. Galperin, M.Y. Genome diversity of spore-forming firmicutes. In The Bacterial Spore: From Molecules to Systems; ASM Press: Washington, DC, USA, 2016; pp. 1-18. [CrossRef]

11. Atarashi, K.; Tanoue, T.; Oshima, K.; Suda, W.; Nagano, Y.; Nishikawa, H.; Fukuda, S.; Saito, T.; Narushima, S.; Hase, K.; et al. Treg induction by a rationally selected mixture of Clostridia strains from the human microbiota. Nature 2013, 500, 232-236. [CrossRef]

12. Gerding, D.N.; Muto, C.A.; Owens, R.C., Jr. Measures to Control and Prevent Clostridium difficile Infection. Clin. Infect. Dis. 2008, 46, S43-S49. [CrossRef] [PubMed]

13. Lawley, T.D.; Clare, S.; Walker, A.W.; Goulding, D.; Stabler, R.A.; Croucher, N.; Mastroeni, P.; Scott, P.; Raisen, C.; Mottram, L.; et al. Antibiotic treatment of Clostridium difficile carrier mice triggers a supershedder state, spore-mediated transmission, and severe disease in immunocompromised hosts. Infect. Immun. 2009, 77, 3661-3669. [CrossRef] [PubMed]

14. Francis, M.B.; Allen, C.A.; Shrestha, R.; Sorg, J.A. Bile Acid Recognition by the Clostridium difficile Germinant Receptor, CspC, Is Important for Establishing Infection. PLoS Pathog. 2013, 9, e1003356. [CrossRef]

15. Moir, A. Germination properties of a spore coat-defective mutant of Bacillus subtilis. J. Bacteriol. 1981, 146, 1106-1116. [CrossRef] [PubMed]

16. Chiang, J.Y.L. Bile acids: Regulation of synthesis. J. Lipid Res. 2009, 50, 1955-1966. [CrossRef]

17. Zwicker, B.L.; Agellon, L.B. Transport and biological activities of bile acids. Int. J. Biochem. Cell Biol. 2013, 45, 1389-1398. [CrossRef]

18. Russell, D.W. The enzymes, regulation, and genetics of bile acid synthesis. Annu. Rev. Biochem. 2003, 72, 137-174. [CrossRef]

19. Hamilton, J.P.; Xie, G.; Raufman, J.P.; Hogan, S.; Griffin, T.L.; Packard, C.A.; Chatfield, D.A.; Hagey, L.R.; Steinbach, J.H.; Hofmann, A.F. Human cecal bile acids: Concentration and spectrum. Am. J. Physiol. Gastrointest. Liver Physiol. 2007, 293, 256-263. [CrossRef] 
20. Hofmann, A.F. The continuing importance of bile acids in liver and intestinal disease. Arch. Intern. Med. 1999, 159, 2647-2658. [CrossRef]

21. Ridlon, J.M.; Harris, S.C.; Bhowmik, S.; Kang, D.J.; Hylemon, P.B. Consequences of bile salt biotransformations by intestinal bacteria. Gut Microbes 2016, 7, 22-39. [CrossRef]

22. Wilson, K.H.; Kennedy, M.J.; Fekety, F.R. Use of sodium taurocholate to enhance spore recovery on a medium selective for Clostridium difficile. J. Clin. Microbiol. 1982, 15, 443-446. [CrossRef] [PubMed]

23. Sorg, J.A.; Sonenshein, A.L. Inhibiting the initiation of Clostridium difficile spore germination using analogs of chenodeoxycholic acid, a bile acid. J. Bacteriol. 2010, 192, 4983-4990. [CrossRef]

24. Sorg, J.A.; Sonenshein, A.L. Bile salts and glycine as cogerminants for Clostridium difficile spores. J. Bacteriol. 2008, 190, $2505-2512$. [CrossRef] [PubMed]

25. Tanaka, M.; Onizuka, S.; Mishima, R.; Nakayama, J. Cultural isolation of spore-forming bacteria in human feces using bile acids. Sci. Rep. 2020, 10, 1-8. [CrossRef]

26. Pelczar, P.L.; Igarashi, T.; Setlow, B.; Setlow, P. Role of GerD in germination of Bacillus subtilis spores. J. Bacteriol. 2007, 189, 1090-1098. [CrossRef]

27. Atluri, S.; Ragkousi, K.; Cortezzo, D.E.; Setlow, P. Cooperativity between different nutrient receptors in germination of spores of Bacillus subtilis and reduction of this cooperativity by alterations in the GerB receptor. J. Bacteriol. 2006, 188, 28-36. [CrossRef]

28. Bhattacharjee, D.; Francis, M.B.; Ding, X.; McAllister, K.N.; Shrestha, R.; Sorg, J.A. Reexamining the germination phenotypes of several Clostridium difficile strains suggests another role for the CspC germinant receptor. J. Bacteriol. 2016, 198, 777-786. [CrossRef]

29. Jr, P.E.C.; Kaiser, A.M.; Mccolm, S.A.; Bauer, J.M.; Vincent, B.; Aronoff, D.M.; Hanna, P.C. Variation in germination of Clostridium difficile clinical isolates correlates to disease severity. Anaerobe 2016, 33, 64-70. [CrossRef]

30. Heeg, D.; Burns, D.A.; Cartman, S.T.; Minton, N.P. Spores of clostridium difficile clinical isolates display a diverse germination response to bile salts. PLOS ONE 2012, 7, e32381. [CrossRef]

31. Shen, A.; Edwards, A.N.; Sarker, M.R.; Paredes-Sabja, D. Sporulation and germination in clostridial pathogens. In Gram-Positive Pathogens; ASM Press: Washington, DC, USA, 2019; pp. 903-926. [CrossRef]

32. Adams, C.M.; Eckenroth, B.E.; Putnam, E.E.; Doublié, S.; Shen, A. Structural and Functional Analysis of the CspB Protease Required for Clostridium Spore Germination. PLoS Pathog. 2013, 9, e1003165. [CrossRef] [PubMed]

33. Francis, M.B.; Allen, C.A.; Sorg, J.A. Spore cortex hydrolysis precedes dipicolinic acid release during Clostridium difficile spore germination. J. Bacteriol. 2015, 197, 2276-2283. [CrossRef] [PubMed]

34. Kochan, T.J.; Foley, M.H.; Shoshiev, M.S.; Somers, M.J.; Carlson, P.E.; Hanna, P.C. Updates to Clostridium difficile spore germination. J. Bacteriol. 2018, 200, 1-12. [CrossRef]

35. Masayama, A.; Hamasaki, K.; Urakami, K.; Shimamoto, S.; Kato, S.; Makino, S.; Yoshimura, T.; Moriyama, M.; Moriyama, R. Expression of germination-related enzymes, CspA, CspB, CspC, SleC, and SleM, of Clostridium perfringens S40 in the mother cell compartment of sporulating cells. Genes Genet. Syst. 2006, 81, 227-234. [CrossRef]

36. Kevorkian, Y.; Shirley, D.J.; Shen, A.; Genetics, M. Regulation of Clostridium difficile spore germination by the CspA pseudoprotease domain. Biochimie 2016, 122, 243-254. [CrossRef]

37. Setlow, P.; Wang, S.; Li, Y.Q. Germination of Spores of the Orders Bacillales and Clostridiales. Annu. Rev. Microbiol. 2017, 71, 459-477. [CrossRef]

38. Paredes-Sabja, D.; Setlow, P.; Sarker, M.R. Germination of spores of Bacillales and Clostridiales species: Mechanisms and proteins involved. Trends Microbiol. 2011, 19, 85-94. [CrossRef]

39. Howerton, A.; Ramirez, N.; Abel-Santos, E. Mapping interactions between germinants and Clostridium difficile spores. J. Bacteriol. 2011, 193, 274-282. [CrossRef] [PubMed]

40. Shrestha, R.; Lockless, S.W.; Sorg, J.A. A Clostridium difficile alanine racemase affects spore germination and accommodates serine as a substrate. J. Biol. Chem. 2017, 292, 10735-10742. [CrossRef] [PubMed]

41. Shrestha, R.; Sorg, J.A. Hierarchical recognition of amino acid co-germinants during Clostridioides difficile spore germination. Anaerobe 2018, 49, 41-47. [CrossRef]

42. Tanaka, M.; Korenori, Y.; Washio, M.; Kobayashi, T.; Momoda, R.; Kiyohara, C.; Kuroda, A.; Saito, Y.; Sonomoto, K.; Nakayama, J. Signatures in the gut microbiota of Japanese infants who developed food allergies in early childhood. FEMS Microbiol. Ecol. 2017, 93. [CrossRef]

43. Fisher, N.; Hanna, P. Characterization of Bacillus anthracis germinant receptors in vitro. J. Bacteriol. 2005, 187, 8055-8062. [CrossRef]

44. Luu, H.; Akoachere, M.; Patra, M.; Abel-Santos, E. Cooperativity and interference of germination pathways in Bacillus anthracis spores. J. Bacteriol. 2011, 193, 4192-4198. [CrossRef] [PubMed]

45. Banawas, S.; Paredes-Sabja, D.; Korza, G.; Li, Y.; Hao, B.; Setlow, P.; Sarker, M.R. The Clostridium perfringens germinant receptor protein GerKC is located in the spore inner membrane and is crucial for spore germination. J. Bacteriol. 2013, 195, 5084-5091. [CrossRef] [PubMed]

46. Bhattacharjee, D.; McAllister, K.N.; Sorg, J.A. Germinants and their receptors in clostridia. J. Bacteriol. 2016, 198, $2767-2775$. [CrossRef] [PubMed] 
47. Bouillaut, L.; Dubois, T.; Sonenshein, A.L.; Dupuy, B. Integration of metabolism and virulence in Clostridium difficile. Res. Microbiol. 2015, 166, 375-383. [CrossRef] [PubMed]

48. Elsholz, A.K.W.; Turgay, K.; Michalik, S.; Hessling, B.; Gronau, K.; Oertel, D.; Mäder, U.; Bernhardt, J.; Becher, D.; Hecker, M.; et al. Global impact of protein arginine phosphorylation on the physiology of Bacillus subtilis. Proc. Natl. Acad. Sci. USA 2012, 109, 7451-7456. [CrossRef] [PubMed] 